\title{
DISENSO, RESISTENCIA Y DIALOGISMO: SOBRE El ENSAYO dE JUAN BENET COMO PUENTE INTELECTUAL ENTRE LA REPÚBLICA Y LA DEMOCRACIA ACTUAL
}

Ken Benson

(Stockholms Universitet)

La ensayística de Juan Benet es polifacética, versátil, tanto sumamente personal como consecuente con sus propias premisas a lo largo de las tres décadas de su producción, desde 1962 hasta los escritos publicados póstumamente. No obstante, su carácter de outsider en las letras españolas de su tiempo, su compleja estética y su antirrealismo han hecho que hasta hoy mismo su escritura sea reiteradamente cuestionada desde una perspectiva ideológica y en ocasiones entendida como alejada de la realidad sociopolítica que le rodea. Puede servir como ejemplo de esta postura el reciente libro de Luis García Montero [2019: 172], en el que enaltece el realismo crítico de Chirbes y critica el antirrealismo de Benet por (supuestamente) pretender «identificar la modernidad con la despolitización de las obras literarias». El presente trabajo va más en línea con otras posturas críticas, como la de Vila [2017: 149], que en cambio señala la importancia del estilo «para depurar el lenguaje de la inercia discursiva impuesta por la retórica de la dictadura» y que «el compromiso operó en la base misma del lenguaje, que era, en realidad, donde lo situaba Sartre». Así, cuando Benet en su temprano ensayo La inspiración y el estilo (1966) [IE'] pretende romper con una supuesta tradición realista de la literatura española, lo que hace es precisamente entroncar con la cultura de los años 1920, situada en esa misma modernidad que los autores a los que Benet muestra como modelos en su ensayo, esto es, los renovadores modernistas de la narrativa europea de su momento, como son los «Henry James, Conrad, Proust, Joyce, Faulkner, Woolf, Döblin...» [Gracia y Ródenas 2011: 143-44]. Mi tesis en este trabajo es, precisamente,

1 Utilizamos siglas para los libros de ensayos de Benet según el listado que figura al final del presente estudio. 
que mediante el disenso [Rànciere] y la resistencia [Foucault²] frente a un discurso monológico, la escritura de Juan Benet constituye un puente intelectual entre la Modernidad bajo la República y la restauración del pensamiento libre que regresó con la democracia actual. Que yo conozca esta tesis no ha sido presentada ni desarrollada en ningún estudio sobre el autor hasta la fecha.

En este trabajo pretendo, por tanto, reivindicar el profundo grado de disenso y resistencia que implicó la radical postura de Juan Benet y su empeño por situar la literatura española en el contexto de la cultura occidental para, de esta forma, romper con la concepción de un supuesto carácter nacional, así como de una supuesta literatura nacional, crítica soslayada pero al mismo tiempo directa al carácter ultranacionalista del discurso franquista. Ahora bien, sostengo que su crítica no es solamente de carácter ideológico, sino que Benet es ante todo crítico con la falta de rigurosidad y consistencia de dicho discurso, que se caracteriza por aseveraciones carentes de fundamento empírico, teórico o científico, según se puede observar en sus diversos ensayos sobre la guerra civil española y sobre la cultura de la postguerra [ver específicamente al respecto los tomos OM y SG del autor]. Quiero, igualmente, mostrar que su capacidad de observación y análisis con respecto a la vida cotidiana, tanto en la postguerra como en los albores de la democracia, reflejan con claridad su capacidad e interés como analista social. Prueba de ello es la recopilación de sus artículos en la prensa que, en efecto, tal y como aseveró Manuel de Lope, muestra a las claras que Benet fue siempre «un comentarista profundo y un excelente observador de situaciones» [PI: 15].

La capacidad e interés de Benet por la argumentación tiene múltiples vertientes, desde tratar cuestiones, gustos e intereses personales, como, por tomar algunos ejemplos, su animadversión por el drama musical y las óperas en directo [en ME: 9-22], su erudita argumentación sobre la deuda de la novela hacia el poema religioso de la antigüedad [PN: 9-95], sobre «los límites de la literatura medieval» [TB: 85-116] o sobre ingeniería mitológica [en «La construcción de la torre de Babel»; TB: 11-68], aparte de los numerosos trabajos con concienzudo conocimiento de tácticas militares en la guerra civil, que explota recurrentemente en su narrativa [TB: 85-116;

\footnotetext{
2 Cfr. Giraldo Díaz (2006: 106), que argumenta que la concepción de resistencia de Foucault es concebida «como un proceso de creación y de transformación permanente; la resistencia no es una sustancia y no es anterior al poder, es coextensiva al poder, tan móvil, tan inventiva y tan productiva como él; existe sólo en acto como despliegue de fuerza, como lucha, como guerra». Es en este sentido que entendemos la resistencia del discurso benetiano frente a las fuerzas del poder establecido en oposición dialéctica a la misma.
} 
$\mathrm{SG}]^{3}$. En esta polifacética plasmación de los múltiples intereses de su pensamiento estriba también de forma inequívoca su disenso con respecto a la cultura popular (tan vigente a partir de la Movida en la primera década de la democracia), pero sobre todo ante lo que, tras su muerte, se ha convertido en un peligro para el pluralismo democrático de Occidente, a saber, el populismo nacionalista, radical, individualista y, sobre todo, antintelectual. Por ello el disenso y la resistencia de los ensayos de Benet durante el franquismo y la primera democracia es tan vigente hoy en día como lo fue en el momento de su escritura, y en consecuencia merece ser analizado también desde la perspectiva de la falta de raciocinio, análisis y rigurosidad que caracteriza el discurso político en la actualidad.

Cabe destacar que, no obstante su versatilidad, la obra ensayística benetiana se caracteriza precisamente por su coherencia y continuidad según apunté supra. No hay transformaciones contundentes en su manera de ver y plasmar su experiencia vital a lo largo de los años, sino puede encontrarse más bien profundización en los argumentos, indagación dialéctica —en continua disputa crítica con sus oponentes-, y dialógica —abierta a diversas interpretaciones y experiencias de la realidad en el sentido bakhtiniano- pese a los cambios políticos y sociales que vivió el autor desde la primera postguerra de la hambruna, pasando por el aislamiento de los años cuarenta y cincuenta, y después por la apertura al turismo y a los mercados internacionales de los años sesenta, la incertidumbre de los setenta por el futuro del país hasta la muerte del dictador, la transición, la democracia, la Movida, y los cambios políticos en el poder gubernamental, síntoma inequívoco de una democracia ya vitalizada en la última década de su vida. Puede mencionarse como ejemplo de esta continuidad y coherencia interna de pensamiento su posicionamiento en contra de la sociología de la literatura y del realismo en general, en cuya línea de pensamiento hay que situar su 'antigaldosianismo', que plasma en diversos escritos en los que desarrolla sus vetas de sorna, cinismo e ironía a niveles quevedescos (cfr. la larga carta al director de Cuadernos para el diálogo con motivo de la invitación que recibió Benet a participar en un número honorífico dedicado al escritor canario [incluida en PI: 37-47]).

El ensayismo de Juan Benet es ciertamente crucial para entender su poética tanto narrativa

3 Cfr. los estudios de Minardi (2005) sobre los ensayos de Benet sobre la guerra civil, destacando la importancia que tiene para Benet la construcción del pensador ilustrado para contrarrestar la ignorancia reinante, así como el trabajo de Catelli (2016). 
[cfr. Benson, 2004] como dramática [cfr. Carrera Garrido, 2015], pero en este trabajo quiero resaltar su importancia como resistencia latente al pensamiento único del poder y a la cultura oficial franquista con su «odio indostánico» [Gracia, 2004: 31] hacia cualquier comportamiento reflexivo y crítico. Quiero igualmente destacar la postura crítica de Benet con respecto a los intereses creados y a la falta de una visión coherente de Estado en el proceso de democratización del país en el periodo de transición y de los albores de la democracia, problemas que siguen siendo de ardiente actualidad, como muestras de su implicación social —en el más amplio sentido de esta palabra, esto es, de preocupación por la construcción de una sociedad plural y con igualdad de derechos-.

Quiero, en este sentido, resaltar que la mera postura (social) y el posicionamiento (intelectual) 'extranjerizante' de Benet con su culto específicamente por la cultura anglosajona, pero igualmente abierto a la internacionalización de la cultura en general, es en sí un posicionamiento irreverente y de resistencia, no ya silenciosa ${ }^{4}$, sino más bien escandalosa (como lo fue más de una de sus comparecencias públicas) ante el caciquismo y nacionalismo del discurso franquista. A nadie como a Benet le gustaba jugar con la irreverencia hacia cualquier pensamiento único y cualquier supuesta verdad que no pudiera ser sometida a pensamiento crítico. Tanto es así que en muchas de sus comparecencias públicas no se sabía si lo que decía lo hacía por convicción o por provocación, así como por el afán de cuestionar cualquier verdad dada como establecida y fija. Esta postura es ya de por sí irreverente con cualquier poder fáctico, sea fascista, republicano, monárquico o democrático, pero indudablemente choca de forma más drástica con todo régimen autoritario como el que en su momento sufrió la generación del autor que nos ocupa. No deja de ser admirable que en su primer libro de ensayos, publicado en 1970, en un ensayo que en principio parece tratar de la enseñanza y específicamente de la enseñanza de historia, Benet haga una loa de los principios democráticos: «La conciencia democrática, tan saludable, único bastión donde a la larga reside el bienestar de un país, parece en parte reñida con la idea de un poder que — tal es el alarde de la historia— cuanto más ha señoreado más trágicas consecuencias ha propinado» [PT: 194]. Igualmente cabe destacar la valentía de Benet cuando

\footnotetext{
4 Aludo al título del libro de Gracia, La resistencia silenciosa, referida al ambiente cultural de la primera postguerra, una resistencia silenciosa que el propio Gracia postula que paulatinamente «dejará de serlo» [Gracia, 35] (esto es, dejará de ser silenciosa, como lo prueban las diversas aportaciones de Benet que aquí tratamos).
} 
en 1968 publica un artículo sumamente crítico con respecto a la falta de rigurosidad científica del Archivo Histórico Militar y su publicación sobre La marcha sobre Madrid, que habría de dar comienzo a un conjunto de monografías «centradas exclusivamente en las operaciones militares de la guerra civil española» [Av1: 59; Pl: 27].

Es en este sentido que propongo que el pensamiento de Benet ha de verse como un baluarte del capital cultural [cfr. Bourdieu, 1988, 1993, 1996] que sobrevivió a la guerra y la postguerra proveniente de la etapa republicana abruptamente rota por el franquismo. El ensayo benetiano ha de verse en consecuencia como un exponente de que ese capital cultural truncado por la guerra civil fue repuesto a través de la inteligencia, el pensamiento crítico y el afán creador de conformar nuevas formas expresivas para formular una experiencia del mundo que entronca con el modernismo cultural de la república, más acorde con la sensibilidad artística y literaria del autor. Este capital cultural se obtiene mediante la lucha por encontrar un lugar de comunicación (en las revistas y editoriales alternativas) que constituye una resistencia en evidente inferioridad de condiciones para llegar a la opinión pública con respecto al poder fáctico del franquismo y la distribución de sus discursos oficiales (como fuera el NODO, lugar de propaganda oficial del régimen y ejemplo extremo de uso estatal para la propaganda del régimen). El lenguaje reflexivo, con sus rasgos dialógicos y su compleja sintaxis, contrasta con el carácter autoritario, monológico y propagandístico del discurso oficial. El carácter opuesto de resistencia (Benet) frente a poder (discurso oficial), en términos foucaultianos, es sintomático y evidente, pero hasta la fecha no ha sido resaltado por la crítica.

Quiero por tanto plantear en este trabajo que el ensayismo de Benet es un exponente de su oposición radical al discurso dominante de la época y como tal constituye una incontestable crítica social, pero sobre todo una crítica intelectual a cualquier tendencia de simplificación y de dominación (de un discurso sobre otro), una crítica por tanto a cualquier expresión de pensamiento único y/o autoritario. Es en este sentido como hay que ver su aportación ensayística y literaria en general como una forma de resistencia, pero también como una construcción de una ética sensible frente a la fuerza militar del poder establecido, y como tal, un ejercicio de poder político, en el sentido que otorga Rancière [2010] a este vocablo, esto es, para otorgar a la dimensión estética su influencia y su trascendencia en el proceso de conformación del poder a través de diversas prácticas discursivas. 
Cabe destacar un rasgo primordial del pensamiento tanto literario, como político y social de Benet: el dialogismo. En efecto, tanto el ensayismo como el conjunto de la escritura benetiana es profundamente dialógico en el sentido de que en él no existe una experiencia o concepción de la verdad sin su contrapartida, su oponente, su 'contraverdad'. Todo su discurso es una expresión de este posicionamiento ante el mundo a partir del cual surge tanto su mundo de ficción [cfr. Benson, 1989] como de pensamiento, según lo desarrolla en ensayos y artículos, así como en las múltiples disquisiciones filosóficas dispersas por sus novelas.

Este carácter dialógico puede detectarse ya en la propia génesis de sus obras ensayísticas, según paso a argumentar. El significado etimológico de ensayo proviene del latín tardío exagium que significa el 'acto de pesar' ${ }^{5}$ un argumento con respecto a otro, lo que podemos entender extensivamente como el acto de sopesar una idea frente a otra. El desarrollo del pensamiento ensayístico se fundamenta, por tanto, en el diálogo, en el intercambio de ideas, en la discusión y en el pensamiento crítico. Si nos fijamos en su breve agradecimiento al conjunto de ensayos compilados en el libro titulado en ciernes $^{6}$, obtendremos una prueba fehaciente del principio dialógico de su ensayística cuando el autor hace mención al carácter social (en cuanto que las ideas surgen de una discusión entre ideas sopesadas, discutidas, argumentadas y contraargumentadas) de la génesis de su pensamiento crítico: «De ser fruto de algo, este libro lo es de innumerables sobremesas. Algunos comentarios aquí expuestos no me pertenecen en exclusiva» [EC: 9$]^{7}$. Este rasgo de dialogismo es fundamental en el pensamiento benetiano, ya que en su pensamiento literario y ensayístico cada idea contiene en sí su propia otredad. En consecuencia, hay que entender su crítica al realismo por considerarlo monológico, en el sentido de que pretende denunciar una realidad determinada, lo que a ojos de Benet es una simplificación de la realidad, cuya complejidad sólo se puede exponer mediante la construcción de un estilo en el que quepan ideas y fuerzas en continua oposición.

En efecto, en ciernes se concibe como el resultado de este diálogo entre iguales (entre amigos) al que el autor alude en las páginas iniciales de este libro, que se discurre sobre su per-

5 Cfr. https://dle.rae.es/?id=FcboTnW

6 Respetamos las minúsculas en el título de la publicación de la primera edición de este libro.

7 Gonzalo Echevarría (2015: 411) apunta que el estilo benetiano como ensayista se relaciona precisamente con su faceta de conversador: "Siempre que se habla de Benet sale a colación esa faceta suya de tertuliano estupendo, de magnífico conversador, algo muy común entre los miembros de su generación. De ahí que me parezca lógico pensar que la vitalidad y la fuerza que distinguen al ensayismo de Benet se nutrieron de la conversación como práctica habitual.» 
cepción del hombre de letras y sobre el discurso estético, donde prevalece la concepción vital e intelectual de la existencia fundamentada en el carácter enigmático del mundo, la naturaleza, la sociedad y el ser humano [cfr. Benson, 2004 y Carrera Garrido, 2015]. Por ello, hay que considerar a Benet como un intelectual imprescindible para comprender la España de su época y para entender su aportación de repensar la estética, incluida su dimensión política, como disenso frente al consenso buscado por el discurso político, valiéndonos de los términos de Rancière [2010]. El disenso de la producción estética forma parte esencial de la poética autorial benetiana, en cuanto que se centra en aquello que el «hombre de ciencias, de negocios o de estado» [EC: 51] no puede llegar a alcanzar, esto es, «ese mundo de claroscuro, de esas fugaces impresiones de lo incierto, de ese telón de fondo que trasciende el saber» [ibid.].

Benet, como buen profesional de la ingeniería que fue, es bien consciente de que para que no se caiga un puente (igualmente válido para la construcción de una sociedad o un estado) ha de estar técnicamente bien diseñado y destaca así la importancia del pensamiento humano como fundamento del desarrollo (tanto técnico, científico, como social). Sin embargo, el punto de inflexión está en que en la filosofía benetiana (que en este sentido es claramente socrática) este conocimiento siempre es limitado y en esa consciencia de la limitación del alcance de la razón humana es, precisamente, donde se levanta el disenso de la producción estética. En consecuencia, Benet considera que el ámbito del mundo de las letras y del arte reside en «la contradicción» [EC: 51], que es donde «para el hombre de letras [...] empieza su zona de sombra, su ámbito de trabajo, su fuente de estímulos e inspiración» [ibid.] y donde imperará ese dialogismo o «lucha de contrarios [...] el imperio del oxymoron: sólo lo fugaz dura y permanece, todo lo verdadero muestra su falsedad, todo lo evidente encierra su misterio» [ES: 53].

En los artículos del autor escritos bajo el franquismo destaca la crítica velada que nos hace cómplices como lectores del estado de las cosas sin tener que hacer una crítica directa, como ocurre en «Barojiana», cuando recuerda que su hermano, «aburrido de este país, se había ido a estudiar a La Sorbona» [OM: 17 , cursiva mía $]^{8}$, o cuando critica la falta de tacto de los

8 En otros lugares el autor es más explícito sobre la represión y la falta de libertad de pensamiento. Cfr. el siguiente pasaje: «Había que andarse con mucho ojo con la publicidad y así, cuando José Suárez Carreño ganó el Premio Nadal 1949, el primero con quien topó fue con un agente de la Social decidido, sin más, a llevárselo a la DGS. No es de extrañar, por consiguiente, que Madrid produjera — sobre todo en ciertos jóvenes que albergaban numerosas inquietudes filosóficas y políticas - una intensa animación centrífuga que sólo lograría calmar aquel afortunado que lograse una beca para la Sorbona» [OM: 80-81]. 
políticos franceses y su condena al régimen español en la $\mathrm{ONU}$, hecho que no tiene ninguna trascendencia política aparte de dejar a los ciudadanos españoles, y al joven Juan Benet de 19 años entre ellos, «en el más escuálido y desamparado aislamiento» [OM: 17]. La sórdida «realidad cotidiana [que], entre 1945 y 1955, ofrecía tan escasos motivos de estímulo y entusiasmo [...]» [OM: 26] y la situación de avidez por recibir noticias — «sobre todo las que no podían ser impresas» [OM: 24-25] — en una cotidianeidad en la que «se vivía del rumor y al mismo tiempo se alimentaba y se desconfiaba de él» [OM: 27] constituyen muestras transparentes y palpables de la experiencia frustrada de la vida intelectual en la más dura postguerra, en la que se carecía del más elemental de los derechos humanos, la libre circulación del pensamiento, ${ }^{9}$ al mismo tiempo que todo ciudadano sufría de necesidades aún más precarias, como el frío y el hambre.

Cabe destacar que este posicionamiento crítico no desaparece con la llegada de la democracia. El pensamiento crítico, fundamento de la democracia, es tan mordaz bajo este periodo histórico como lo había sido bajo la dictadura, con la gran diferencia de que ahora la crítica puede formularse de forma totalmente abierta, sin necesidad de salvar censuras o asumir riesgos personales. Así, pasado año y medio del comienzo de la transición a la democracia, el pensador Benet lanza fuertes críticas sobre los nuevos políticos democráticos y su incapacidad de superar las mismas taras que había señalado con respecto al poder franquista: la incompetencia, la falta de miras y la carencia de una política elaborada para el bien de todos los ciudadanos por parte del poder fáctico en cuestión:

\footnotetext{
Y hasta este momento — que ya dura año y medio— el político español sólo ha demostrado una cosa: su torpeza. A pesar de los ciento y pico partidos no se ha visto una idea nueva, distinta de las ya existentes en España en 1936 o en el mundo en la actualidad. Y [...] no acierto a ver un solo programa de partido completo y atractivo, una exposición brillante, una declaración de principios inéditos, un léxico con gracia, una fórmula que convenza. Hasta ahora sólo se han visto rivalidades, quisquillosidades y una extremada afición al vedetismo. Es decir, las más sobresalientes notas de carácter, a pequeña escala, del dictador. La conclusión más elemental y evidente salta a la vista: nos hallamos muy lejos todavía de habernos extraído el veneno que nos inoculó el franquismo [Av1: 184, cursiva mía].
}

\footnotetext{
9 Hay que entender el pensamiento literario dentro de su ideología liberal, en la tradición ilustrada, donde la libertad de pensamiento y acción es un axioma central para el ser humano. Cfr. Gay [2014: 307]: "Juan Benet vivió buena parte bajo el Régimen franquista; pero esa no fue la única tiranía a la que se enfrentó; también a aquella otra representada por una opción ideológica como la única oposición legítima frente a la dictadura. Ante estas imposiciones evidentes, Benet hizo uso de su derecho a disentir, sin dejar de compartir algunas ideas con esa ideología opositora, pero sin abdicar de su libertad de pensamiento.»
} 
Este posicionamiento estético e intelectual dialógico, de pensamiento crítico y de disenso, es crucial para comprender el conjunto de la ensayística benetiana, pues informa toda su concepción del pensamiento, en el que también se incluye la concepción de la memoria como nuclear para comprender y valorar tanto su labor ensayística como su narrativa, si bien también supeditado a la importancia del estilo y del lenguaje $\mathrm{e}^{10}$. La memoria constituye un motor de la creación para Benet, a quien, por más que tuviera una memoria portentosa (como prueban los múltiples detalles en lo que más se parece a un libro de memorias dentro de la producción benetiana, Otoño en Madrid hacia 1950 [OM]), le interesaba menos lo que recordaba que la manera en que se conformaban en la memoria esos recuerdos (tan dispar al orden cronológico y causal, motivo por el cual es reincidente su crítica feroz a la novela socialrealista de la postguerra franquista con su tradición galdosiana ${ }^{11}$ ) y, consecuentemente, le interesaba menos lo que recordaba nítidamente que aquello que se le borraba, aquello que no se podía asir, que se confundía en la mente rememorante ${ }^{12}$. La memoria constituye, como es bien sabido, un eje temático central de su magnífica segunda novela, Una meditación (de cuya publicación se cumple este año el 50 aniversario), pero el funcionamiento de la memoria guarda también una relación directa con lo que él consideraba gran literatura ('el gran estilo'), aquella que está «en gran medida informada por la incertidumbre, la memoria, la fatalidad y el temor» [EC: 61]. En esa incapacidad de la memoria (incluida la memoria histórica) de conformar consenso surge la densa narrativa benetiana como expresión de disenso con respecto a cualquier simplificación de la realidad y de la historia.

La labor de Benet, como la de tantos otros intelectuales de la época en la resistencia, es de crucial importancia como contrapeso al pensamiento único del poder tomado por las armas militares, que vencieron pero, como se suele repetir desde Unamuno, no convencieron. La labor

10 Cabe mencionar que ya Carlos Barral [1969], cuyo posicionamiento ideológico es transparente, criticó la extrema pobreza literaria y estilística de la poesía y la narrativa de la primera postguerra, hecho con el que se enfrenta Benet. Ignacio Echevarría [2015: 418] pondera, por su parte, la capacidad de Benet de crear debate público, fenómeno que echa en falta actualmente: «esta manera de fomentar la reflexión y el debate público, me parece el rasgo más personal de Benet y el que determinó su importante influencia en el campo de las ideas. Y es el que más echo en falta en el ensayismo y, sobre todo, del articulismo español en la actualidad.»

11 Cfr. Benet [1970a y 1970b].

12 «La memoria guarda y archiva el objeto reducido a una imagen sucinta y cuando ha de recurrir a él lo que le es suministrado ya no es exactamente igual al objeto original (en cuanto impresión de los sentidos, se entiende) sino algo deformado, más reducido y más económico.» [PT: 38] «La memoria devora a la existencia; no recuerda lo vivido sino que reproduce lo recordado. Una vez que lo nuevo queda alistado en las filas de la memoria no se presentará ya nunca como fue sino — precisamente- como fue registrado» [PT: 94]. 
de resistencia es precisamente la de convencer al lector de que la libertad es el medio fundamental para el desarrollo intelectual del ciudadano. Es así como, superadas las limitaciones extremas de pobreza en las dos primeras décadas de postguerra, a partir de los años sesenta, los ensayos, así como los artículos periodísticos o las revistas intelectuales, tienen gran importancia para la resistencia intelectual ante el discurso único del poder franquista ${ }^{13}$.

La importancia de Benet con sus rompedores escritos en esta década han de incorporarse a la historia de las ideas de este momento crucial para la conformación del puente entre el pensamiento bajo la democracia prefranquista y la postfranquista. Pues si bien el pensamiento de Benet no tuvo una repercusión social o intelectual en su momento, como consecuencia de que no tenía gran distribución por razones obvias, su resistencia intelectual ha tenido gran importancia en la creación de un habitus que permitiera, tras la muerte de Franco, que gran parte de la sociedad estuviera no sólo preparada sino también predispuesta a exigir el único camino posible tras el largo letargo de la postguerra, a saber, una sociedad con libertad democrática y, por tanto, abierta al diálogo, al pluralismo y al pensamiento crítico. ${ }^{14}$ Principios que Juan Benet defendió y mantuvo desde el periodo más crudo y aislado de la postguerra bajo el régimen fascista de Franco hasta el proceso de democratización del país tras la muerte del dictador y la delicada transición.

Podemos, por tanto, concluir que el posicionamiento estético de librepensador en radical oposición a cualquier verdad prestablecida tiene gran importancia para comprender el paso a la democratización tras la muerte de Franco y tras la delicada transición, de forma que el pensamiento de Benet ha de verse como un puente entre la culturalmente avanzada sociedad española bajo la República y la democracia postfranquista actual, sin perder el posicionamiento de disenso fundamental del arte como un poder fáctico continuamente crítico con respecto al poder establecido, tal y como lo conciben Rancière y Bourdieu. El posicionamiento benetiano es totalmente transparente en lo que se refiere a la defensa de la libertad de pensamiento, así como

13 Coincidimos con Chicharro Chamorro [1995: 44] cuando trata el simplismo de la clasificación política («realista de izquierdas; estilista de derechas»), mientras que Benet buscaba provocar «el debate dialéctico, lejos de todo gregarismo».

14 Puede objetarse que es improbable que la hermética escritura de Benet, literatura de minorías, pueda crear un cambio de habitus, en el sentido bourdieuniano, pero basta con ver cómo su colocación periférica en diversas historias literarias se ha ido reposicionando. Así, por ejemplo, en la más reciente, Gracia y Ródenas [2011], que reivindican su importancia como escritor y pensador con claridad ejemplar, permiten colegir que ha habido un cambio en la percepción de su importancia y su influencia en el pensamiento intelectual. 
en lo referente a su incuestionable resistencia antifascista, pero también, teniendo en cuenta la coherencia de su pensamiento en los albores de la democracia, cabe pensar que habría reaccionado con la misma fortaleza tanto contra el populismo político actual como contra las palabras vacuas de muchas expresiones de políticos en la actualidad, de igual forma que lo hizo, según hemos podido comprobar, en los primeros años de democratización y de transición del país ante actuaciones políticas que consideraba no estar a la altura de las circunstancias. A casi tres décadas de lla muerte de Benet, nada más alejado y opuesto al mensaje simplista del discurso político actual que la ambición de crear ese gran estilo que en su incierta complejidad busca con su retórica y su búsqueda de formas expresivas renovadoras alejarse de lo cierto y profundizar en lo incierto. En este sentido, el pensamiento (literario, cultural, político, intelectual y social) de Benet mantiene gran actualidad, aparte de ser un exponente significativo para comprender la situación intelectual del país en las dos últimas décadas del franquismo y bajo las dos primeras décadas de la transición y democracia de España y que son fundamentales para comprender la cultura literaria más reciente, pues en ella Benet lleva a cabo «la reclamación teórica primero y la práctica novelesca después del escritor que modernizó radicalmente las nociones sobre la novela que siguen vigentes a comienzos del siglo XXI» [Gracia y Ródenas, 2011:114].

Quiero por ello clausurar reflexionando sobre la importancia del posicionamiento crítico de Benet y su implacable actualidad cuando pensamos en la sociedad de consumo y el capitalismo avanzado de nuestros días, que «cultivan la miseria cultural» [García Montero, 2019: 185]. Esta sociedad en la que «el ser analfabeto resulta motivo de orgullo» (ibid.) y frente a la cual resulta primordial aprovechar «todo el equipaje del pensamiento crítico para intentar devolverle la confianza a una ilusión democrática» [Id:: 193). La postura crítica de Benet fue tan crucial en el momento que le tocó vivir como lo es en el mundo actual, caracterizado por la postverdad, motivo por el cual merece la pena volver continuamente sobre el pensamiento literario de Juan Benet para analizar y comprender las limitaciones y los peligros del presente actual, a tres décadas de la muerte de nuestro autor. 


\section{Bibliografía}

ENSAYOS DE BENET CITADOS

Av1 Artículos. Volumen 1 (1962-1977), Madrid: Ediciones Libertarias, 1983.

CB La construcción de la torre de Babel, Madrid: Siruela, 1990.

EC en ciernes, Madrid: Taurus, 1976.

IE La inspiración y el estilo, Madrid, Revista de Occidente, 1966.

OM Otoño en Madrid hacia 1950, Madrid: Alianza Tres, 1987

PI Páginas impares, Madrid: Alfaguara, 1996.

PN del pozo y del Numa, Madrid: La gaya ciencia, 1978.

PT Puerta de tierra, Barcelona: Seix Barral, Biblioteca breve de bolsillo, 1970.

SG La sombra de la guerra. Escritos sobre la Guerra Civil española, Madrid: Taurus, 1999.

OtRAS REFERENCIAS CITADAS

BARRAL, Carlos: «Reflexiones acerca de las aventuras del estilo en la penúltima literatura española». Cuadernos para el diálogo, XIV Extraordinario ('30 años de Literatura: narrativa y poesía española 1939-1969', 1969, pp. 39-42.

BENET, Juan: «Reflexiones sobre Galdós», Cuadernos para el Diálogo, XXIII Extraordinario, diciembre, 1970a, pp. 13-15.

BENET, Juan: «Respuesta al señor Montero», Cuadernos para el Diálogo, XXIII, Extraordinario, diciembre, 1970b, pp. 75-76.

BENSON, Ken: Razón y espíritu. Análisis de la dualidad subyacente en el discurso narrativo de Juan Benet. Stockholm: Stockholms Universitet, Romanska Institutionen, 1989.

BENSON, Ken: Fenomenología del enigma. Juan Benet y el pensamiento literario postestructuralista. Amsterdam-New York: Rodopi, 2004.

BOURDIEU, Pierre: Homo Academicus. Stanford: Stanford University Press, 1988. 
BOURDIEU, Pierre: The Field of Cultural Production: Essays on Art and Literature, ed. Randal Johnson. New York: Columbia University Press, 1993.

BOURDIEU, Pierre: The Rules of Art: Genesis and Structure of the Literary Field. Stanford: Stanford University Press, 1996.

CARRERA GARRIDO, Miguel: El enigma sobre las tablas: análisis de la dramaturgia completa de Juan Benet. Madrid: Consejo Superior de Investigaciones Científicas, Instituto de Lengua, Literatura, y Antropología, 2015.

CATELLI, Nora: Guerra y literatura. Madrid: Libros de la resistencia, 2016.

CHICHARRO CHAMORRO, Antonio: "Juan Benet y el pensamiento literario del medio siglo», Cuadernos hispanoamericanos, no. 537 (marzo 1995), pp. 43-54.

ECHEVARRÍA, Ignacio: «En torno al ensayismo de Juan Benet», en Gracia, Jordi y Ródenas, Domingo (ed.), Ondulaciones. El ensayo literario en la España del siglo XX. Madrid - Frankfurt am Main: Iberoamericana - Vervuert, 2015, pp. 411-418.

GAY, Juan Pascual: "Job y la inspiración: notas sobre el pensamiento literario de Juan Benet». Moenia, núm. 20 (2014), pp. 305-325.

GARCÍA MONTERO, Luis: Las palabras rotas, Madrid: Alfaguara, 2019.

GIRALDO DÍAZ, Reinaldo: «Poder y resistencia en Michel Foucault», Tabula Rasa. Revista de Humanidades, universidad Colegio Mayor de Cundinamarca, Colombia.

GRACIA, Jordi: La resistencia silenciosa. Fascismo y cultura en España, Barcelona: Anagrama, 2004 .

GRACIA, Jordi y RÓDENAS, Domingo: Historia de la literatura española. Derrota y restitución de la modernidad. 1939-2010. Barcelona: Crítica, 2011.

MINARDI, Adriana: «Hacer la Historia: el sentido de práctica discursiva en Qué fue la guerra civil, de Juan Benet. La construcción del intelectual después de Franco». Biblioteca virtual universal, s.p. https://documentop.com/el-sentido-de-practica-discursiva-en-que-fue-la-guerra-civilde-juan-_59883c441723ddb404629b05.html, 2005. 
Ken Benson

RANCIÈRE, Jacques: Dissensus: on politics and aesthetics, London: Continuum, 2010.

VILA SÁNCHEZ, José Antonio: «Los intelectuales, el compromiso y el medio siglo español».

Artes del ensayo. Revista internacional sobre el ensayo hispánico, Núm. 1 (2017), pp. 140-152. 